\title{
A Study on Hospitality and Tourism Teachers' Teaching Competence to Use Inquiry-Based Teaching into "Project Study" Curriculum of Senior High and Vocational Schools
}

\author{
Chia-Ling Shih, Chin-Wen Liao, Chang-Fu Lin, and Tsai-Ku Liao
}

\begin{abstract}
This study mainly intends to investigate the current status that hospitality and tourism teachers' instruction of inquiry-based teaching into the "project study" curriculum of senior high and vocational high schools, and analyzes the differences among hospitality and tourism teachers of high schools and vocational high schools with different background variables in terms of the project study instruction competence, inquiry-based teaching competence, and introduction of project study competence to inquiry-based teaching. By taking hospitality and tourism teachers of high schools and vocational high schools nationwide as the research object, this study is adopted the stratified cluster sampling to extract teachers from 38 schools, after summarized the collected data of current statuses, SPSS is applied to carry out the data analysis then.
\end{abstract}

Index Terms-Hospitality and tourism teachers, high schools and vocational high schools hospitality group, inquiry-based teaching, project study, teaching competence.

\section{INTRODUCTION}

\section{A. Research Background}

In Taiwan's “Twelve-year National Fundamental Education", the "actualization of vocational high schools" implementation program indicated that in addition to enhance professional and practical curriculum, the development of school-based curriculum shall promote the project study curriculum; moreover, for teachers' development of teaching profession, it has not only improved teaching standard for teachers, but also encouraged them to participate in training programs and industry-academy activities, as well as rewarded teachers who participated or guided various contests and competitions; in terms of students' performance of diversified learning, it has not only increased their learning effectiveness, but also enhanced students' professional skills, incubated their project study competence, as well as encouraged them to participate in various proficiency tests and contents [1].

The purpose of "project study" curriculum is to incubate students to have the ability to integrate professional theories and knowledge skills to develop empirical experiences, so as to train students for their capacity for independent thinking

Manuscript received April 18, 2015; revised July 22, 2015.

C.-L. Shih, C.-F. Lin, and T.-K. Liao are with the Department of Industrial Education, National Changhua University, Taiwan, R.O.C (e-mail: malisa168@yahoo.com.tw, terence650607@hotmail.com, tsaikuliao@gmail.com).

C.-W. Liao is with the Department of Industrial Education and Technology, National Changhua University of Education (NCUE), Taiwan (e-mail: tcwliao@cc.ncue.edu.tw). and incubate them to have the spirit of mutual cooperation and learning. In terms of the curriculum contents and teaching activities, they should provide students with learning opportunities of observation, exploration, discussion and creation, which can make them to be capable of having the creative thinking, independent judgment, change adaptability and self-development [2]. Therefore, in the process of project study, in addition to cultivate students to elaborate their imagination and creativeness by using the theories and skills that they've learnt, it can also be applied to the product design, manufacturing or problem-solving. Thus, it is able to improve students for strengthening their problem-solving capability and skill learning, as well as advance teamwork and interpersonal interaction.

\section{B. Research Motivation}

The arrangement and design of "project study" curriculum is different from the previous cramming method of teaching modes, and the inquiry-based guiding method can allow students to learn from it, and further to understand the important function of inquiry-based teaching in the "project study" curriculum, so as to show the meaning of inquiry-based teaching. Thus it proves that "project study" curriculum is really suitable to use the inquiry-based teaching to achieve the teaching goals, thus this study tends to understand hospitality and tourism teachers of high schools and vocational high schools for their current status of the "project study instruction competence", "inquiry-based teaching competence" and "introduction of project study competence to inquiry-based teaching", and this is the first research motivation of this study.

Along with facing new curriculum of "project study", teachers have to complete the curriculum planning in advance, and play the role to initiate students' learning motivations and lead students to complete the project study course, in order to use the study to investigate the difference of hospitality and tourism teachers of high schools and vocational high schools with different background variables for their "project study instruction competence", and this is the second motivation.

In the situation of inquiry teaching, it guides students to investigate directions, assist students in carrying out systematical science thinking, advance students' higher-order thinking abilities, problem-solving abilities, instructors have to use methods and strategies to guide learners to carry out communication and negotiation so as to form a common view for knowledge [3], if teachers are not equipped with inquiry teaching abilities, how students can learn such ability, thus this study tended to investigate the current status of "inquiry-based teaching competence" for those hospitality 
and tourism teachers with different background variables of high schools and vocational high schools, and this is the third research motivation of this study.

The purpose of "project study" curriculum is to incubate students to have the ability to integrate professional theories and knowledge skills together with the empirical experiences, so as to focus on their thinking ability and train students for their capacity for independent thinking and incubate them to have the spirit of mutual cooperation and learning. In terms of the teaching activities, teachers should be based on the goal of curriculum, teaching outline, student ability and teaching resource, and adopted proper teaching methods to achieve the expectative effectiveness of teaching [2], thus, based on such study, it tended to investigate the current status of "introduction of project study competence to inquiry-based teaching" for hospitality and tourism teachers with different background variables of high schools and vocational high schools, and this is the fourth research motivation of this study [4].

\section{Research Objects}

Based on these aforesaid research motivations, research objects of this study are as follows:

1) To understand the current status of hospitality and tourism teachers of high schools and vocational high schools to the "project study instruction competence", "inquiry-based teaching competence" and "introduction of project study competence to inquiry-based teaching".

2) To investigate the difference of hospitality and tourism teachers" "project study instruction competence" with different background variables of high schools and vocational high schools.

3) To investigate the difference of hospitality and tourism teachers' "inquiry-based teaching competence" with different background variables of high schools and vocational high schools.

4) To investigate the difference of hospitality and tourism teachers' "introduction of project study competence to inquiry-based teaching" with different background variables of high schools and vocational high schools.

\section{RESEARCH DESIGN AND IMPLEMENTATION}

This study is adopted questionnaire survey as the research method to collect the research sample of current status, after carried out the literature review, organization and analysis, it established the theoretical basis of this study. Then, it applied the "scale of hospitality and tourism teachers' inquiry-based teaching competence to introduce the project study curriculum into the inquiry-based teaching competence high schools and vocational high schools" to conduct the survey with taking teachers from all high schools and vocational high schools that have hospitality group as the population, then adopted stratified cluster sampling to carry out the questionnaire survey, after summarized and organized these returned questionnaire, it used the statistical package software SPSS to conduct the further analysis [5]. In addition, according to these analytic results, it has inferred the research conclusions and suggestions then.

The research framework of this study is showed as in Fig. 1.

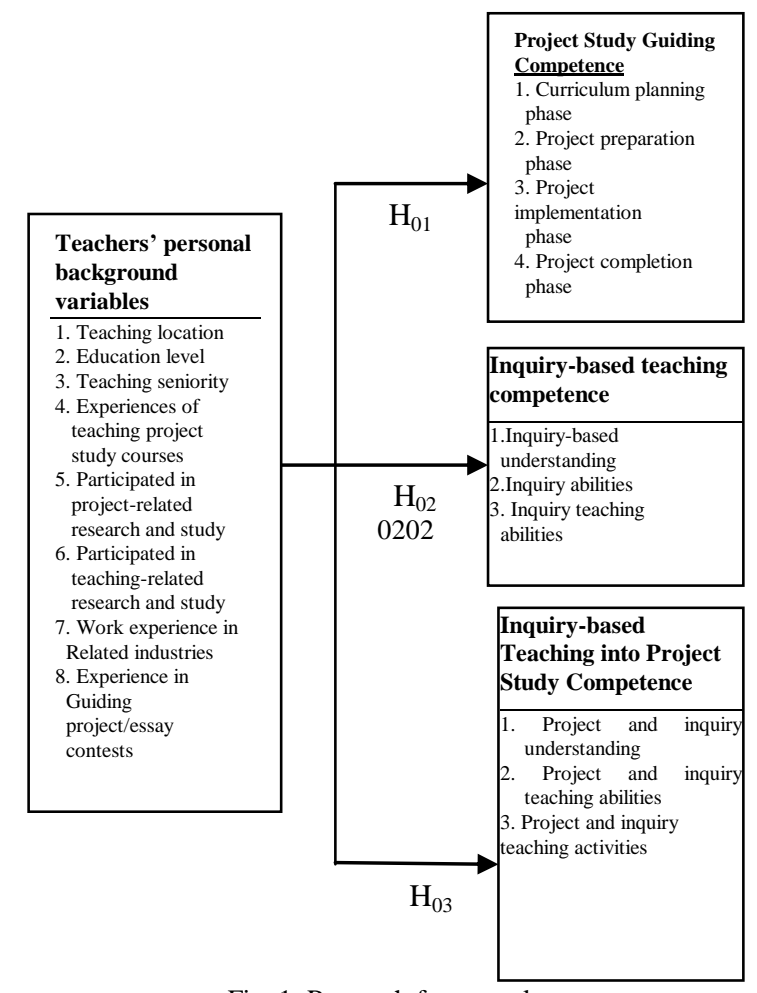

Fig. 1. Research framework.

\section{DATA ANALYSIS AND DISCUSSION}

This study took all hospitality and tourism teachers of high schools and vocational high schools as the population and research object, and carried out the questionnaire survey in accordance with the stratified cluster sampling. Samples were obtained from all schools with hospitality group, and the ratio distributions for the number of schools and teachers are as follows: sampled 129 teachers from 11 schools in north area; 104 teachers from 8 schools in central area; 104 teachers from 13 schools in south area; and 35 teachers from 6 schools in east area; totally collected 318 copies of questionnaire from 35 schools, the number of valid questionnaire is 308 and 10 invalid copies. In the questionnaire, the fundamental data of teachers' individual background variables (including teaching location, education level, teaching seniority, teaching experience of project study curriculum, participated in project-related research and study courses, participated in related inquiry-based teaching research and study courses, related work experience and experiences in guiding project/essay contests) will be displayed in descriptive statistics, such as frequency distribution and percentage, to understand the distribution status of these fundamental data for survey samples. The statistical analysis results are as in Table I.

This study is used the descriptive statistical analysis to understand the current status for hospitality and tourism teachers of high schools and vocational high schools when they introduce the "project study" curriculum into inquiry-based teaching; in addition, t-Test and One-way ANOVA are applied to examine the fitness and difference for teachers' personal background variables to the project study instruction competence, inquiry-based teaching competence, and introduction of project study competence to inquiry-based teaching, and these verified results of research hypotheses with different background variables are listed in Table II. 
TABLE I: DATA ANALYSIS TABLE OF HOSPITALITY AND TOURISM TEACHERS' BACKGROUND VARIABLE OF High SCHOOLS AND VOCATIONAL High SCHOOLS

\begin{tabular}{|c|c|c|c|c|}
\hline Variables & Option Item & Population & Percentage & Percentage \\
\hline \multirow{4}{*}{ Teaching location } & North area & 89 & 28.9 & 28.9 \\
\hline & Central area & 82 & 26.6 & 55.5 \\
\hline & South area & 104 & 33.8 & 89.3 \\
\hline & East area & 33 & 10.7 & 100.0 \\
\hline \multirow{2}{*}{ Education level } & college, university & 110 & 35.7 & 35.7 \\
\hline & Master's Degree, Ph.D. & 198 & 64.3 & 100.0 \\
\hline \multirow{4}{*}{ Teaching seniority } & Less than 1 year $\sim 5$ years & 94 & 30.5 & 30.5 \\
\hline & More than 5 years $\sim 10$ years & 128 & 41.6 & 72.1 \\
\hline & More than 10 years (including) $\sim 15$ years & 52 & 16.9 & 89.0 \\
\hline & More than 15 years & 34 & 11.0 & 100.0 \\
\hline \multirow{3}{*}{$\begin{array}{l}\text { Teaching experience of project study } \\
\text { curriculum }\end{array}$} & No class given & 75 & 24.4 & 24.4 \\
\hline & Class given and teaching seniority is less than 2 years & 119 & 38.6 & 63.0 \\
\hline & $\begin{array}{l}\text { Class given and teaching seniority is more than } 2 \text { years } \\
\text { (including) }\end{array}$ & 114 & 37.0 & 100.0 \\
\hline \multirow{2}{*}{$\begin{array}{l}\text { Participated in project-related research and } \\
\text { study courses }\end{array}$} & Never participated & 108 & 35.1 & 35.1 \\
\hline & Participated before & 200 & 64.9 & 100.0 \\
\hline \multirow{2}{*}{$\begin{array}{l}\text { Participated in related inquiry-based } \\
\text { teaching research and study courses }\end{array}$} & never participated & 217 & 70.5 & 70.5 \\
\hline & participated before & 91 & 29.5 & 100.0 \\
\hline \multirow{3}{*}{ Related work experience } & Never have & 100 & 32.5 & 32.5 \\
\hline & Seniority of hospitality and tourism is less than 3 years & 147 & 47.7 & 80.2 \\
\hline & $\begin{array}{l}\begin{array}{l}\text { Seniority of hospitality and tourism is more than } 3 \text { years } \\
\text { (including) }\end{array} \\
\end{array}$ & 61 & 19.8 & 100.0 \\
\hline \multirow{2}{*}{$\begin{array}{l}\text { Experiences in guiding project/essay } \\
\text { contests }\end{array}$} & No guidance given & 133 & 43.2 & 43.2 \\
\hline & Guidance given & 175 & 56.8 & 100.0 \\
\hline
\end{tabular}

$N=308$

TABLE II: SUMMARIES OF VERIFIED RESULTS OF RESEARCH HYPOTHESES WITH DIFFERENT BACKGROUND VARIABLES

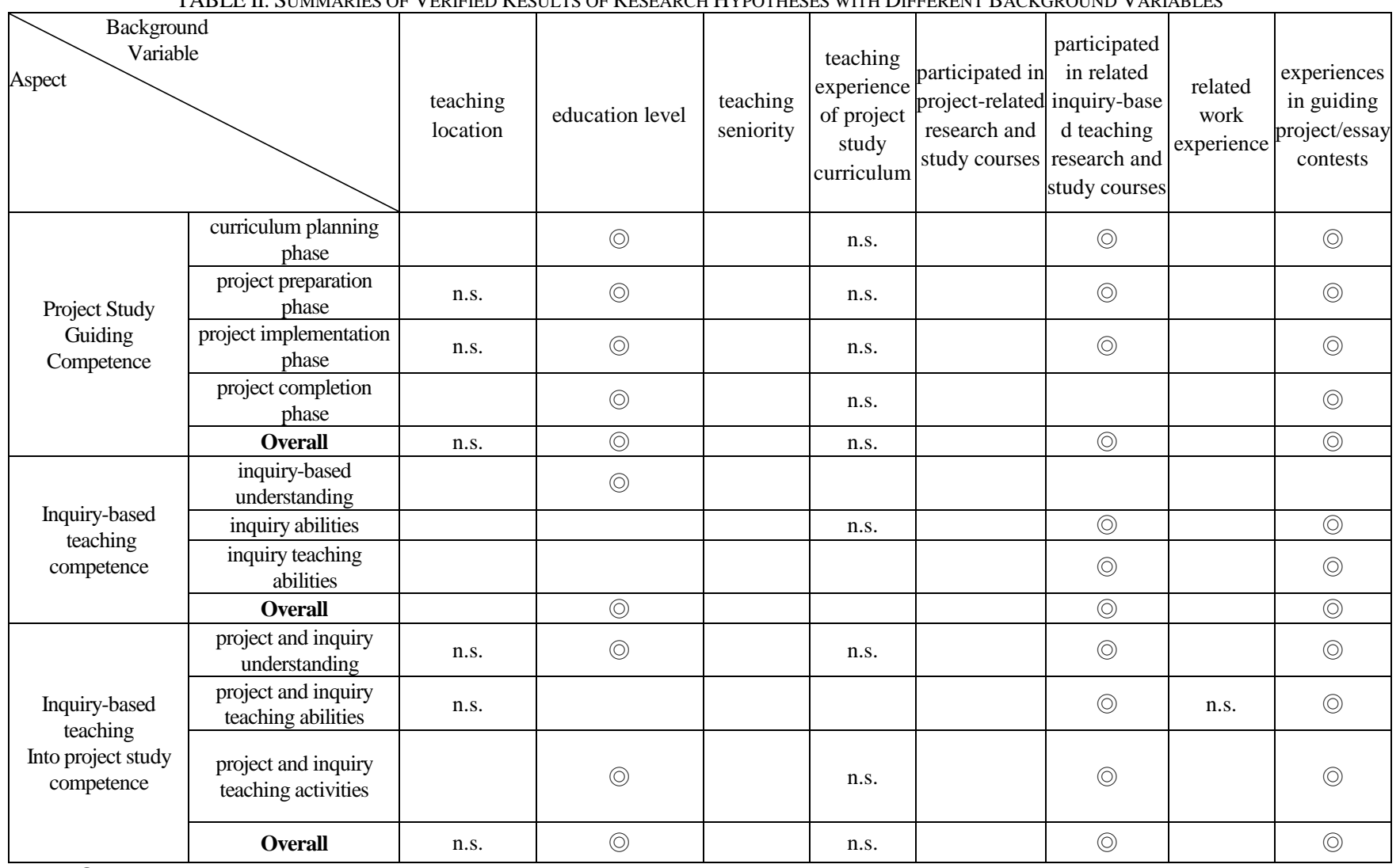

Note: ")" indicates that not yet reached a significant difference; null hypothesis rejected.

"n.s." indicates that reached a significant difference, and it cannot discover the actual difference after carried out Post hoc Comparison. 


\section{CONCLUSIONS AND SUGGESTIONS}

This study is tented to investigate the current status for hospitality and tourism teachers of high schools and vocational high schools to project guiding competence, inquiry-based teaching competence and introduction of project study competence to inquiry-based teaching; in addition, it analyzed, generalized and organized the verified results and then made conclusions, and then proposed specific suggestions according to these conclusions, so as to provide hospitality group centers, schools, educators and follow-up researchers as a reference.

\section{A. Conclusions}

1) Hospitality and tourism teachers of high schools and vocational high schools reached "fitted" situation for the "project study instruction competence", "inquiry-based teaching competence" and "introduction of project study competence to inquiry-based teaching". However, it still needs to enhance the project and inquiry teaching competence to fit the professional and diversified abilities for the project study.

2) Teachers with a Master's degree or Ph.D., and participated in related inquiry-based teaching research and study courses before, and have experiences in guiding project/essay contests will have higher "inquiry-based teaching competence".

3) Teachers who are teaching in southern Taiwan areas, with a Master's degree or Ph.D., implemented the instruction of project study curriculum for more than 2 years (including), participated in related inquiry-based teaching research and study courses before, and have experiences in guiding project/essay contests will have higher "using inquiry-based teaching into project study competence".

4) Teachers who are teaching in eastern Taiwan area (including off-shore islands), with a Master's degree or $\mathrm{Ph}$.D., implemented the instruction of project study curriculum for more than 2 years (including), participated in related inquiry-based teaching research and study courses before, and have experiences in guiding project/essay contests will have higher "project study instruction competence".

\section{B. Suggestions}

1) Fully improve teachers' inquiry abilities, the education authorities shall properly plan the comple enquiry-based competence research and study in order to make full-time teachers to experience the inquiry-based learning for deeper understand, as well as cultivate teachers' inquiry abilities and inquiry-based teaching abilities.

2) Hospitality Centers shall arrange related research course or workshops by focusing the features of hospitality group to implement inquiry-based teaching. On-site tour in related enterprises can have either theoretical or practical applications in order to advance teachers to trigger students' imagination and creativity in the project study curriculum, thus it shall be included the planning of project study research and study.

3) To advocate every school that shall focus on their local characteristics and integrated with local industries; however, in this study, the question item: "I truly understand the local culture, industrial resources and local characteristics for schools' location" has the lowest level of competence, which also indicated that teachers have not yet very familiar to local culture, local characteristics for schools' locations and it suggested to handle related research and study to enhance teachers for such competence, so as to guide students to promote the project research on local specialties.

4) Encourage teachers to establish a professional social community to share with teaching methods and competitive experiences; in addition, encourage teachers to establish a professional social community to make those teachers with experiences in guiding project/essay contests to share the experiences of their teaching methods and competitions, that is, it cannot only enhance teachers' competence in the professional social community, but also can use the experience inheritance to improve the competitive performance in the future.

5) Establish the dual-teacher teaching mode for the project study curriculum. It suggested schools can adopt the dual-teacher method in the project study curriculum, which mainly arranged teachers with higher seniority of instruction to cooperate with those teachers with lower seniority of instruction as assistants. The dual-teacher method can bring students with more professional guidance and advice; in the meantime, it also can enhance teachers without instruction experience or lower seniority of instruction for their empirical experiences.

\section{Follow-up Research}

\section{1) For research objects}

The research object of this study is selected by using stratified cluster sampling and based on their location, the number of schools and teachers; however, due to the different areas, the proportion of schools and teachers will also be varied, thus the questionnaire returned rate may affect the inference of research results, thus it suggested that the follow-up researchers should increase the returned rate while it is divided by areas, so as to make such research to be more representative and completed.

\section{2) For research methods}

This study is only used the quantified data of questionnaire survey to carry out the data analysis. Due to the correlation and repetition of some questions, the participants may be unable to understand those questions or have deviated explanation for them, or they didn't give $100 \%$ response to such question. Thus, it suggested that those follow-up researchers can focus on "quality" research with adopting the in-depth interview, case study, etc., to make up the insufficiency of "quantity" research, then analyze and compare with the questionnaire survey results, thus the research results would have more referential values as well.

\section{3) For research tools}

For these research tools of this study, although the reliability and validity of question contents with every level have been carried out the item analysis, reliability analysis and the validity review for expert contents, however it still 
needs the follow-up researches to make further tests and comparisons to make the research tools to be more precisely in this study. In addition, the researcher discovered that some teachers, during the data statistical process, would have the situation of $\ulcorner$ consistency $\lrcorner$ for their answers of each aspect, thus, in order to certainly measure teachers' actual perception, it suggested that place some reverse questions in each scale to determine the reliability and validity for questionnaire.

\section{REFERENCES}

[1] Ministry of Education. (2013). Vocational High School Actualization of 12-Year Fundamental Education. [Online]. Available: http://12basic.edu.tw/Detail.php?LevelNo=534

[2] Ministry of Education. (2013). Vocational School-Based Curriculum. [Online]. Available: http://tpde.tchcvs.tc.edu.tw/course/

[3] C. H. Tseng, "Investigation of science teachers participated in learning community their inquiry-based teaching professional development changes," Ph.D. dissertation, National Changhua University of Education, Taiwan, 2013.

[4] H. H. Hu, Project Study-Hospitality Group, New Taipei City: Top Ching, 2012.

[5] M.-L. Wu, SPSS Statistics Practical Learning: Questionnaire Analysis and Applied Statistics, New Taipei: Acore, 2011.

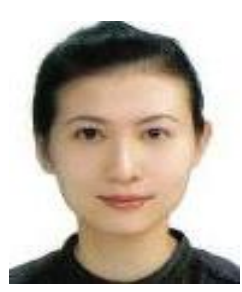

Chia-Ling Shih is a doctoral student of the Department of Industrial Education and Technology, National Changhua University of Education (NCUE), Taiwan and now she is a high school teacher in Taichung, Taiwan.

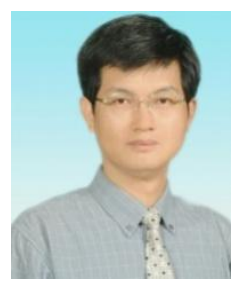

Chin-Wen Liao received both his M.S. and Ph.D. degrees in industrial education from National Taiwan Normal University, Taiwan, R.O.C. in 1994 and 2002, respectively. Since August 2011, he has been a professor in the Department of Industrial Education and Technology at National Changhua University of Education (NCUE) in Taiwan, R.O.C. He teaches courses in technology and vocational education, energy education, course and teaching, organizational learning. His research interests include technology and vocational education, teacher education, energy education of technology, and learning organization.

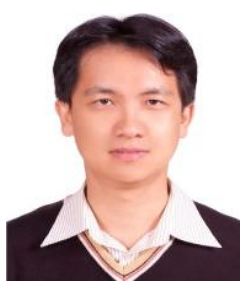

Chang-Fu Lin received his M.S. degree at the Department of Graduate Institute of Primary and Secondary Education from National Chiayi University in 2003 , and currently he is a doctora student at the Department of Industrial Education from National Changhua University, Taiwan, R.O.C

Since August 2012, he has been a director of general affairs office in Tonan Senior High School in Taiwan, R.O.C. Since August 2000, he has taught courses in everyday science technology in the same school.

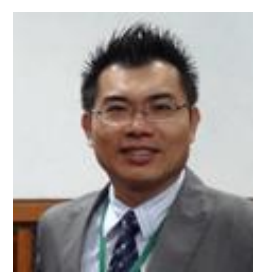

Tsai-Ku Liao received his M.S. degree at the Department of Geography from National Taiwan Normal University in 2006, and currently he is a doctoral student at the Department of Industrial Education from National Changhua University, Taiwan, R.O.C. Since August 2008 , he has been a director of Student Affairs and Library in National Taichung First Senior High School (TCFSH) in Taiwan, R.O.C. Since August 1998, he has taught courses in geogrpahy, GIS, monographic study in the same school. 